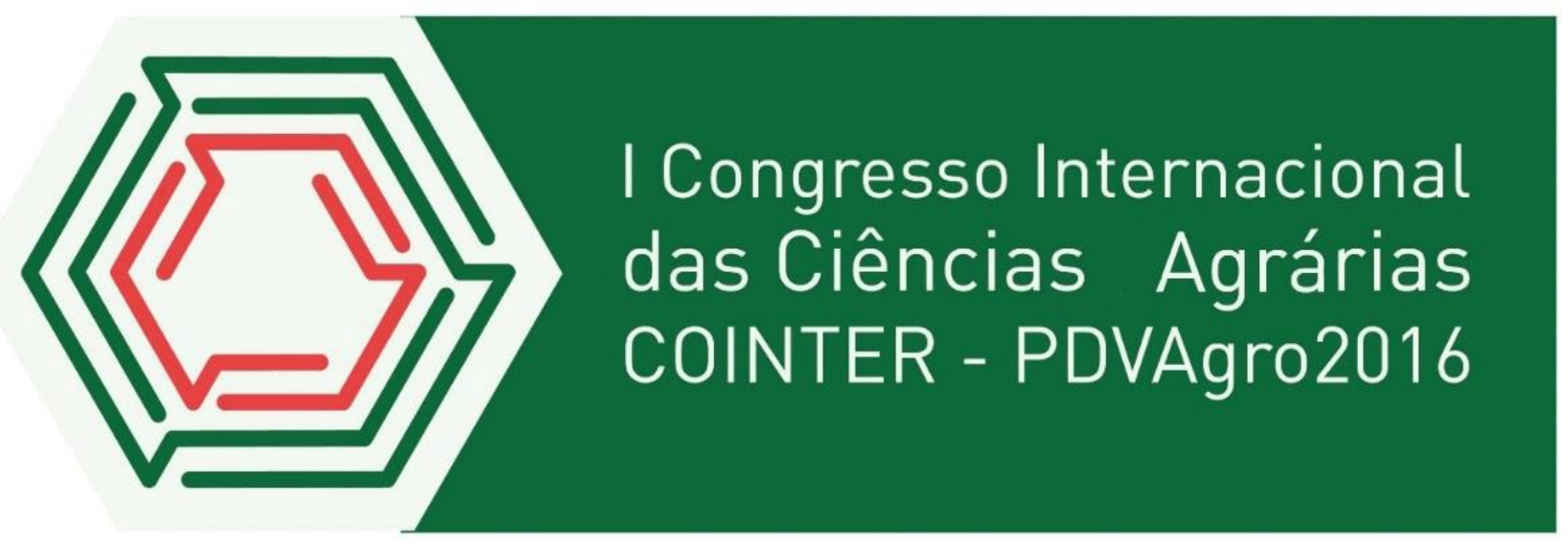

\title{
HORTAS COMUNITÁRIAS: FERRAMENTA PARA QUALIDADE DE VIDA E SEGURANÇA ALIMENTAR
}

Apresentação: Relato de Experiência

José Denilson da Silva ${ }^{1}$; Adair José da Silva ${ }^{2}$; Anderson Lucas da Silva ${ }^{3}$; Ronaldo Alves de Oliveira Filho ${ }^{4}$

\section{Introdução}

O intercâmbio de atividades do IFPE Campus Vitória de Santo Antão com as comunidades rurais contribui para a construção coletiva de conhecimentos, bem como para o fortalecimento da agricultura familiar. A interação dos alunos com os agricultores e agricultoras configura-se como estratégia para a abordagem da nova assistência técnica e extensão rural. A assistência técnica proposta neste estudo visa fortalecer a importância da Agroecologia, que de acordo com CAPORAL et al (1994), deve ser entendida como a ciência ou disciplina científica que apresenta uma série de princípios, conceitos e metodologias para estudar, analisar, avaliar e desenhar agroecossistemas sustentáveis, com o propósito de permitir a implementação de estilos de agricultura e de desenvolvimento rural com maiores níveis de sustentabilidade a curto, médio e longo prazos.

\section{Relato de Experiência}

A comunidade de Queimados localiza-se na cidade de Feira Nova, e a cerca de 36,7 km do IFPE - Campus Vitória e tem no cultivo de mandioca, batata doce, milho, feijão, inhame e criações

\footnotetext{
${ }^{1}$ Bacharelado em Agronomia, IFPE-CVSA, denisonsila@gmail.com

${ }^{2}$ Bacharelado em Agronomia, IFPE-CVSA, adjairsilva.agronomia.ifpe@gmail.com

${ }^{3}$ Bacharelado em Agronomia, IFPE-CVSA, andersonagro1@ hotmail.com

${ }^{4}$ Mestre em Ciências agrarias, IFPE-CVSA, ronaldo.alves@ vitoria.ifpe.edu.br
} 
de ovinos, caprinos e bovinos, sendo assim suas principais fontes de renda, somada aos incentivos dos programas sociais do Governo Federal.

Foi verificado que na comunidade $65 \%$ dos agricultores compravam suas hortaliças nas feiras livres, o que é algo um pouco alarmante, tendo invista que essa é uma comunidade agrícola. Observou-se que quem tinha mas interesse em produzir as hortaliças eram as mulheres da comunidade, que geralmente tem um tempo livre maior que os homens que trabalham no campo.

Neste trabalho realizou-se atividades coma a integração comunidade / IFPE, sempre privilegiando o conhecimento endógeno dos agricultores para que possamos não impor nossos conhecimentos, e sim trabalharmos em parcerias, para almentarmos no fim, a qualidade de vida e aumento de renda da comunidade, realizou-se a construção de hortas na comunidade, pois foi uma demanda relatada pelas agricultoras locais, juntamente com as hortas as confecções de biofertilizantes e compostagem.

Foto 1- práticas de produção de hortas.
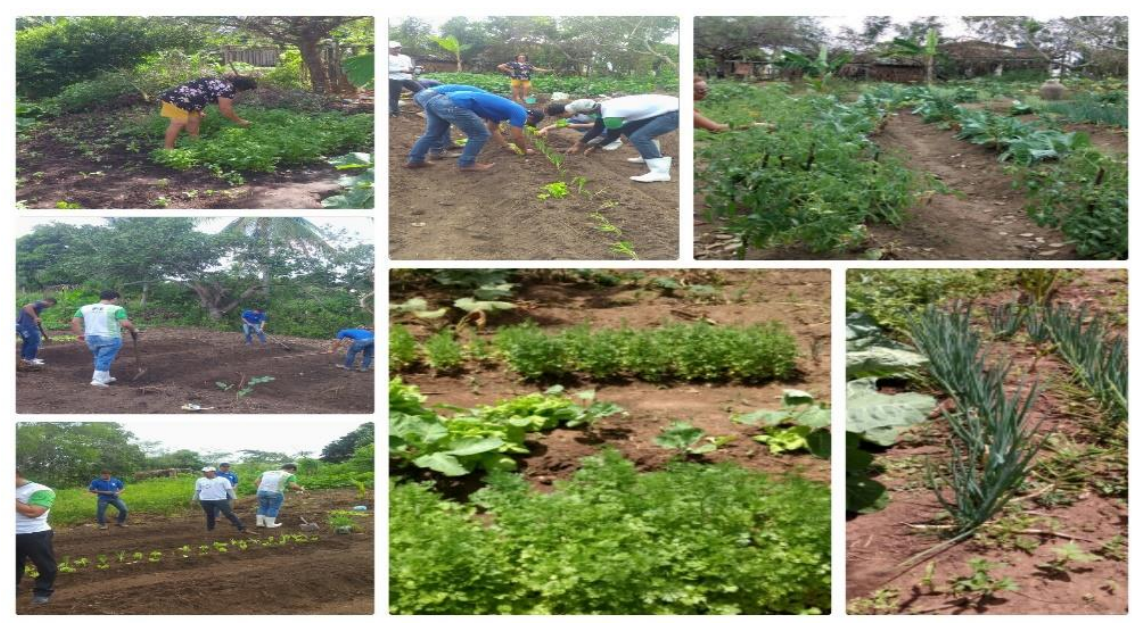

\section{Considerações}

As atividades realizadas foram e continuam sendo de suma importância para o desenvolvimento sustentável da comunidade, pois além de levar mas qualidade de vida para os agricultores, vem trazendo um aumento nas rendas das famílias.

\section{Referências}

CAPORAL, Francisco Roberto; COSTABEBER, José Antônio. Por uma nova extensão rural: fugindo da obsolescência. Rev. Reforma Agrária, Campinas: ABRA, v.24, n. 3, set/dez, 1994.(o mesmo texto pode ser encontrado na Rev. Extensão Rural, Santa Maria: DEAER/CPGER,UFSM, v. 2, n. 2, jan/dez., 1994). 
IBGE, Censo Demográfico 2010. Disponível em www.censo2010.ibge.gov.br. Acesso em 02/10/2016. 